\title{
Air quality and health impacts in the Eastern Mediterranean Region: an eye on COVID-19
}

\author{
Mazen Malkawi, ${ }^{1}$ Basel Al-Yousfi ${ }^{2}$ and Ahmed Mandil ${ }^{3}$
}

${ }^{1}$ Advisor for Environmental Health Exposure, World Health Organization Regional Office for the Eastern Mediterranean Centre for Environmental Health Action (CEHA), Amman, Jordan. ${ }^{2}$ Director, World Health Organization Regional Office for the Eastern Mediterranean Centre for Environmental Health Action (CEHA), Amman, Jordan. ${ }^{3}$ Coordinator, Research and Innovation, World Health Organization Regional Office for the Eastern Mediterranean, Cairo, Egypt. (Correspondence to: A. Basel Al-Yousfi: alyousfia@who.int).

Citation: Malkawi M; Al-Yousfi AB; Mandil A. Air quality and health impacts in the Eastern Mediterranean Region: an eye on COVID-19. East Mediterr Health J. 2021;27(01):3-4. https://doi.org/10.26719/2021.27.1.3

Copyright (C) World Health Organization (WHO) 2021. Open Access. Some rights reserved. This work is available under the CC BY-NC-SA 3.0 IGO license (https://creativecommons.org/licenses/by-nc-sa/3.o/igo).

Air quality is intimately linked to human activities, climate, atmosphere and ecosystems. Many of the anthropogenic contributors to air pollution are also sources of greenhouse gases including $\mathrm{CO}_{2}$ and other short-lived climate pollutants, such as Ozone and black carbon, which greatly contribute to the climate change phenomenon and its adverse effects on human health. Unfortunately, fragile and dry ecosystems prevailing in most of our countries in the Eastern Mediterranean Region may be implicated for exacerbation of this air pollution and climate change dilemma even more severely.

Air pollution sources in the Region differ significantly from those in other parts of the world, in part due to the arid nature and high prevalence of natural dust, as well as the widespread practice of biomass and solid waste burning. More than $50 \%$ of air pollutants were reported to come from natural sources, while the other half is blamed on the transportation sector, energy production, industrial emissions, agricultural operations, wastes open burning practices, and household use of unclean fuels for cooking, heating ad lighting (1).

From photochemical smog and dust hanging over our cities, to the prefiltration of kitchen and secondhand tobacco smoke inside the homes, air pollution poses a major threat to public health. More than $90 \%$ of the people living in our urban areas are exposed to air pollutants levels that exceed World Health Organization (WHO) guideline limits for health protection (2). Children, women, older people and outdoor workers, among other vulnerable groups, are at greater risks as they are subjected to higher levels of air pollution. The combined effects of ambient and household air pollution are causing approximately 500000 premature deaths every year in the Region (3). This is largely a result from increased morbidity and mortality attributed to stroke, heart disease, chronic obstructive pulmonary disease, lung cancer, asthma and acute respiratory infections.

Air quality management policies and actions are still far below the optimal levels that control air pollution in the Region due to the following major gaps and challenges: poor environmental monitoring and reporting mechanisms; poor commitment; poor coordination between the different related sectors; weak health surveillance systems, and lack of heath based standards in almost all countries of the Region (4).

Living in a healthy environment is an integral human right, and it is the responsibility of governments to provide clean air to their citizens to breathe safely. There are numerous options available to national governments and local authorities on know-how to support actions to improve air quality. Some of these options are designed to make sure that capacity and processes are built up to enable decision-makers to recognize where air pollution comes from and what emission rates and atmospheric concentrations are, and what actions are to be taken in order to reduce air pollution and exposure levels. Although institutional capacities are limited in this regard, there are still numerous WHO resources available to help countries understand their air pollution problems and identify priority actions and interventions to protect public health and the surrounding environment in which we live.

While controlling the natural sources of air pollution is perhaps difficult and may need long-term mitigation, curtailing other man-made sources is relatively feasible and can be done immediately. cost effective interventions are readily available, yielding health gains and co-benefits surpassing necessary investments. Fortunately, indoor air pollution is a problem for which we know the solutions. All countries where many people still cook using biomass and other dirty fuels, such as kerosene, can develop programmes to improve access to clean energy sources, fuels and technologies. Secondhand smoke, as well as other sources of indoor air pollution such as incense and candles burning, should be minimized or even eliminated, especially in well-insulated living environments with air conditioning and restricted ventilation.

In order to meet the WHO guideline levels for safe, healthy ambient air quality, countries must address the major sources of air pollution in different contexts and resource settings. These may include: development of evidence on health impacts of natural air pollution (dust and sea salt particulate matter), including relevant mitigation interventions to be enhanced and used in the development of national air quality standards and management; rapidly phase out health-harmful subsidies for dirty fuels and polluting industries and introduce penalties for polluters and/or taxes on pollution; adopt and strictly enforce emissions standards for all pollutants 
in all relevant sectors, including industry, energy, transport, waste and agriculture; redirect investment to health promotion, accessible alternatives including clean transport, renewable energy and/or to provide universal health coverage; improve housing conditions and ensure access to clean energy sources for indoor cooking, heating and lighting; and include air quality measures In urban, rural and transport planning at city, regional and national level, including measures to encourage modal shift and active mobility, noting the additional benefits to health, wellbeing and reduction of health inequalities (5).

To help our Member States focus their actions on the most efficient way to prevent and reduce the pollution risks and adverse health effects, WHO has identified the key air pollutants with negative impacts on people's health. WHO is continuously reviewing and analyzing the accumulated scientific evidence and relying on upon experts' opinion and advice to draw tangible conclusions on the level of risk due to indoor and outdoor air pollution. WHO has been providing technical support at countrylevel on best practices to both reduce air pollution and mitigate public health effects. Special attention should be given to reducing emissions of short-lived climate pollutants, as this can provide health benefits in three key ways: 1 ) directly from reduced air pollution and related illhealth; 2) indirectly from reduced ozone and black carbon effects on extreme weather and agricultural production (adversely affecting food security); and 3) from other types of health benefits that are not associated with air pollution, but may accrue as a result of certain mitigation actions, such as improved diets or more opportunities for safe active travel and enhanced physical activity.

The WHO Regional Centre for Environmental Health Action (WHO/CEHA) in Amman, Jordan, has developed and commenced the implementation of a regional plan of action on air pollution and health in the Eastern Mediterranean Region for 2017-2022 (3). The plan of action takes into consideration the regional context, including climate and local air pollutants, availability of monitoring data and the status of national surveillance systems and policies for controlling air pollution. The plan is linked to relevant targets of the Sustainable Development Goals (SDGs) and also considers developments as opportunities for synergies at global and regional levels, including the Paris Agreement on Climate Change (2015) (6), Marrakech Declaration on Health, Environment and Climate Change (2016) (7), the Arab Strategy on Health and Environment 2017-2030 (8), and the regional work priorities for the WHO Eastern Mediterranean Region (9).

The ongoing COVID-19 pandemic has revealed, like never before, the fragility of our societies and economies, stressing the urgent need to improve our relationship with the natural world. Early studies projected that air pollution increases the likelihood, vulnerability and severity of succumbing to COVID-19. WHO in collaboration with other international organizations are supporting research to verify such findings and to answer several important questions such as: do air conditioning and ventilation systems increase the risk of virus transmission? If so, how can this be managed? Can we use air conditioning in the context of COVID-19? Can fans and indoor air circulation be used safely in indoor spaces and how can ventilation reduce the risk of contracting COVID-19 in transportation facilities? All of these questions and worries are giving us yet another good reason to urgently improve the quality of the air we breathe. On the other hand, COVD-19 lockdowns and other public health precautionary measures have provided clear evidence that high levels of air pollution can be readily reduced, not necessarily through banning human activities, but through healthy and wise socioeconomic recovery, controlling industrial and transportation emissions, and utilizing clean and green fuels, energies, planning and technologies.

\section{References}

1. Karagulian F, Belis CA, Dora CFC, Prüss-Ustün AM, Bonjour S, Adair-Rohani H, et al. Contributions to cities' ambient particulate matter (PM): A systematic review of local source contributions at global level, Atmos Environ. 2015;120(11):475-483.

2. World Health Organization. WHO air quality guidelines. Global update 2005. Particulate matter, ozone, nitrogen dioxide and sulfur dioxide; Geneva: World Health Organization; 2005.

3. World Health Organization. Infographic air pollution - the invisible killer. Geneva: World Health Organization; 2019 (https:// www.who.int/airpollution/infographics/en/).

4. World Health Organization Regional Office for the Eastern Mediterranean (WHO/EMRO). Regional plan of action for implementation of the roadmap for an enhanced global response to the adverse health effects of air pollution, EM/RC64/INF.DOC.3. Cairo: WHO/EMRO; 2017 .

5. World Health Organization Regional Office for the Eastern Mediterranean (WHO/EMRO). Accelerating regional implementation of the Political Declaration of the Third High-level Meeting of the General Assembly on the Prevention and Control of Noncommunicable Diseases, EM/RC66/7. Cairo: WHO/EMRO; 2019.

6. Natural Resources Defense Council (NRDC). The Paris agreement on climate change. Paris: NRDC, 2015 (https://www.nrdc.org/ sites/default/files/paris-climate-agreement-IB.pdf).

7. World Health Organization. Ministerial declaration on "Health, Environment and Climate Change". Geneva: World Health Organization; 2016.

8. World Health Organization Regional Office for the Eastern Mediterranean (WHO/EMRO), League of Arab States (LAS), United Nations Environment Program (UNEP). Arab strategy and framework of action on health and environment 2017-2030. Amman: WHO/EMRO, LAS, UNEP; 2017.

9. Al-Yousfi AB; Bakir H; Malkawi M. The environmental health nexuses within the strategic roadmap: regional work priorities for the WHO Eastern Mediterranean Region. East Mediterr Health J. 2018;24(2):117-118. 